\title{
Thermal, Mechanical and Morphological Properties of Poly (Hydroxybutyrate) and Polypropylene Blends After Processing
}

\author{
Wagner Mauricio Pachekoski*, José Augusto Marcondes Agnelli, Lauriberto Paulo Belem \\ Department of Materials Engineering, Federal University of São Carlos, \\ Rod. Washington Luis, Km 235, P.O. Box 676, 13560-905 São Carlos - SP, Brazil
}

Received: November 2, 2008; Revised: March 25, 2009

\begin{abstract}
The ever increasing accumulation of plastic waste in the environment has motivated research on polymers that degrade rapidly after being discarded as possible substitutes for conventional inert plastics. Biodegradable polymers can be an alternative, since they have non-toxic residual products and low environmental permanence. Poly (hydroxybutyrate) is a biodegradable polymer with a strong potential for industrial purposes, but its thermal instability and fragility limit its applications. Thus, an alternative to improve the processability and properties of poly (hydroxybutyrate) is to mix it with another polymer, not necessarily a biodegradable one. In this work, different mixtures of poly(hydroxybutyrate) or PHB and polypropylene or PP were extruded and injected. After processing, the blends were studied and their miscibility, mechanical properties and degradability in different soils were analyzed. The main results indicated that the PHB/PP blends had better mechanical properties than pure PHB, as well as improved immiscibility and higher degradation in alkaline soil. The poly-hydroxybutyrate/ polypropylene blends showed a tendency for lower crystallinity and stiffness of the polymer matrix, proportional to the amount of polypropylene in the blends, rendering them less stiff and fragile. The degradation tests showed that both pure PHB and blends with 90\% PHB and 10\% PP were degraded, with loss of their mechanical properties and weight.
\end{abstract}

Keywords: poly (hydroxybutyrate), biodegradable polymers, polymer blends

\section{Introduction}

Ever increasing aggressiveness to the environment caused mostly by human negligence and imprudence has become an issue of worldwide concern. The growing accumulation of plastic waste is considered the main contributing factor for environmental degradation resulting from the indiscriminate disposal and long degradation time of conventional polymers, which has been estimated at one hundred years or more ${ }^{1}$. Thus, research is focusing increasingly on the development of polymers that combine the desired functionality during use and rapid degradation after disposal as a viable alternative to conventional nondegradable polymers, mostly for applications in which long degradation times are undesirable. Biodegradable polymers fit this context perfectly, since they degrade rapidly and contain nontoxic end products which have low permanence in the environment and are completely metabolized by soil microorganisms ${ }^{2}$.

Poly(hydroxybutyrate) - PHB is a biodegradable thermoplastic polyester produced by bacterial fermentation, whose biodegradation time is short. PHB has a very high potential for industrial applications ${ }^{3}$ due to its high crystallinity (50-70\%), excellent gas barrier (water vapor permeability around $560 \mathrm{~g} . \mu \mathrm{m} / \mathrm{m}^{2} /$ day) and physical properties similar to those of polypropylene ${ }^{4}$. PHB has an elasticity modulus of $3 \mathrm{GPa}$ and tensile strength at break of $25 \mathrm{MPa}$. However, PHB has some disadvantages, such as high fragility ${ }^{5}$, showing 3-5\% tensile elongation at break, and low thermal stability above its melting point ${ }^{6}$, with marked degradation starting at $200{ }^{\circ} \mathrm{C}$.

An alternative to improve these properties and $\mathrm{PHB}$ processability is to mix it with another polymer, not necessarily a biodegradable one. Abbate et al. ${ }^{7}$ studied PHB blends with ethylene-propylene (EPR) and ethylene-vinyl acetate (EVA) copolymers. They found that the
PHB/EPR blends were immiscible, presenting distinct and unaltered $\mathrm{T}_{\mathrm{m}}$ (melting temperature) and $\mathrm{T}_{\mathrm{g}}$ (glass transition temperature). The PHB/EPR blends also showed considerably improved elongation at break and higher tensile strength. Greco et al. ${ }^{8}$ studied PHB and poly(vinil acetate) - PVAc blends and characterized their thermal and morphological properties and their biodegradation rates. These blends were found to be miscible, with $\mathrm{T}_{\mathrm{m}}$ and $\mathrm{T}_{\mathrm{g}}$ values intermediate between those of PHB and PVAc. The poly(vinyl acetate) reduced the crystallinity and crystallization rate of $\mathrm{PHB}$, which constituted the most marked phenomenon at higher concentrations of PVAc. Avella et al. ${ }^{9,10,11}$ investigated PHB blends with poly(ethylene oxide) - PEO, analyzing their thermal and mechanical behavior, crystallization and morphology. They found that the PHB/PEO blends were immiscible, but observed a decrease in the values of $\mathrm{T}_{\mathrm{m}}$ and $\mathrm{T}_{\mathrm{g}}$ of $\mathrm{PHB}$ proportional to the amount of PEO in the blend. They also observed a reduction in the crystallinity of $\mathrm{PHB}$, which they attributed to interference of the PEO domains in the growth of PHB spherulites.

The present work therefore presents the results of different poly(hydroxybutyrate) - PHB and polypropylene - PP blends produced in a single screw extruder and injected, and analyzes the miscibility of the blends by differential scanning calorimetry (DSC) and scanning electron microscopy (SEM). A comparison is also made of the mechanical properties of pure PHB and of PHB blends containing different concentrations of polypropylene to reduce the fragility of PHB. An evaluation is also made of the degradation of the $90 \%$ $\mathrm{PHB} / 10 \%$ polypropylene blend in soil with a known composition, but with different $\mathrm{pH}$ values, based on an analysis of the mass loss and the variation of its mechanical properties. 


\section{Experimental}

\subsection{Material}

The PHB was produced by PHB Industrial S/A and is sold under the brand name Biocycle ${ }^{\circledR}$. The material used in this work came from batch number FE-64, with $\overline{M w}=150,000$ g.mol ${ }^{-1}$ and a polydispersivity of 3.2.

TS 6100 polypropylene (Quattor Petroquímica) was used. This material is a homopolymer, with $\overline{M w}=360,000 \mathrm{~g} \cdot \mathrm{mol}^{-1}$ and a melt flow index of $16 \mathrm{~g} / 10$ minutes, which is used in injected parts for general use and in thin wall products.

\subsection{Preparation of samples}

The PHB and PP were first oven-dried in circulating air at $50{ }^{\circ} \mathrm{C}$ for two hours. PHB/PP blends containing 90, 75 and 50\% of PHB in weight were then mixed by hand prior to extrusion. The mixtures were extruded in a GERST mod. $25 \times 24$ single screw extruder. The processing conditions are presented at Table 1 .

After processing, all the compositions were pelletized with a Jethro pelletizer. To improve the pelletization procedure, the extruded materials were allowed to rest for thirty days to enhance their crystallinity.

After pelletization, the various $\mathrm{PHB} / \mathrm{PP}$ blends were injected in an Arburg ${ }^{\circledR}$ Allrounder 270V 300-120 Injector, using an ASTM ${ }^{\circledR}$ specimen tests injection mold for tensile and impact tests. Table 2 describes the conditions employed for the injection of the PHB/PP blends.

\subsection{Differential Scanning Calorimetry (DSC)}

To evaluate the melting temperature $\left(\mathrm{T}_{\mathrm{m}}\right)$ of $\mathrm{PHB}, \mathrm{PP}$ and their blends, the DSC data were recorded in a NETZSCH ${ }^{\circledR}$ DSC 200 calorimeter in the temperature range of $25^{\circ} \mathrm{C}$ (room temperature) to $220^{\circ} \mathrm{C}$ and under argon at a flow rate of $40 \mathrm{~mL} / \mathrm{min}$. The samples $(5 \mathrm{mg})$ were placed in aluminum crucibles and heated from 25 to $220{ }^{\circ} \mathrm{C}$ at a heating rate of $10{ }^{\circ} \mathrm{C}$ minutes $\left(1^{\text {st }} \mathrm{scan}\right)$, followed by rapid quenching at $25^{\circ} \mathrm{C}$. They were then heated from 25 to $220{ }^{\circ} \mathrm{C}$ at heating rate of $10{ }^{\circ} \mathrm{C}$ minutes $\left(2^{\text {nd }} \mathrm{scan}\right)$ to determine the $\mathrm{T}_{\mathrm{m}}$.

\subsection{Scanning Electron Microscopy (SEM)}

For the Izod impact test, PHB/PP samples were first broken up and immersed in toluene for two days to remove the PP phase. After removal of the PP, the test specimens were dried and vacuum coated with a thin gold/platinum layer. These specimens were analyzed in a Leica ${ }^{\circledR}$ Stereoscan 440 scanning electron microscope under 5,000, 3,000 and $1,000 \mathrm{x}$ magnification, operating at a voltage of $10 \mathrm{kV}$ to produce the micrographs.

\subsection{Mechanical tests}

Tensile tests were carried out according to the ASTM $^{\circledR}$ D-638 standard in an Instron ${ }^{\circledR}$ 5500R universal testing machine with

Table 1. Extrusion conditions for the PHB/PP blends.

\begin{tabular}{cccccc}
\hline \multicolumn{3}{c}{ Temperature $\left({ }^{\circ} \mathrm{C}\right)$} & & \multicolumn{2}{c}{ Velocity $(\mathrm{rpm})$} \\
\hline $\mathrm{V}$ & $1^{\text {st }}$ zone & $2^{\text {nd }}$ zone & Melted & Screw & Engine \\
\hline 125 & 140 & 150 & 193 & 30 & 100 \\
\hline
\end{tabular}

a gauge distance $\left(1_{0}\right)$ of $115 \mathrm{~mm}$, at a rate of $5 \mathrm{~mm} / \mathrm{min}$. Seven $165 \times 12.5 \times 3.2 \mathrm{~mm}$ test specimens of each sample were tested, and mean values and standard deviations were evaluated.

Notched Izod impact tests were performed in a Ceast 6545100 Izod impact tester, applying an impact energy of $2.75 \mathrm{~J}$, according to the ASTM $^{\circledR}$ D-256 standard. Twelve $63 \times 12.5 \times 3.2 \mathrm{~mm}$ test specimens of each sample were tested to evaluate the mean values and standard deviations.

Hardness was measured in a Shore Conveloader under a load of $5 \mathrm{~kg}$ and a retention time of 15 seconds, employing the D2 type Shore Durometer hardness test, according to the Brazilian ABNT NBR 7456 standard for "D2" type rigid polymeric materials. The hardness was determined based on the mean value of six measures for each sample, carried out on test specimens injected for the impact strength tests according to the ASTM $^{\circledR} 256$ standard.

\subsection{Accelerated degradation tests in soil}

A homogeneous soil was prepared by mixing dark brown silt having a solid specific weight of $25.6 \mathrm{kN} \mathrm{m}^{-3}$ with $0.3 \mathrm{~mm}$ of $\mathrm{n}^{\circ} 50$ General Brazilian coarse sand, organic matter (cow manure) and distilled water. About $7 \mathrm{~kg}$ of this homogeneous soil mixture was then placed in $30 \times 20 \times 14 \mathrm{~cm}$ steel trays.

To evaluate the influence of $\mathrm{pH}$ on the degradation of the samples, degradation tests were performed on soil samples having three different $\mathrm{pH}: 7,9$ and 11 . The $\mathrm{pH}$ was controlled with a $\mathrm{pH}$ meter and a calomel electrode. Calcium hydroxide and hydrogen chloride were used as $\mathrm{pH}$ correctors.

Ten PHB and ten PHB/PP (90/10) test specimens were buried on the trays with the soil mixtures at each $\mathrm{pH}$. To evaluate their mass loss, the test specimens were removed from the trays at 15-day intervals, washed, dried with compressed air and weighed on a Bosch ${ }^{\circledR}$ S-200 analytical balance, after which they were buried again on the same trays. After ninety days, five samples of each material were subjected to stress/strain tests, following the ASTM ${ }^{\circledast}$ D 638 standard.

\section{Results}

\subsection{Differential Scanning Calorimetry (DSC)}

The DSC curves shown in Figure 1 reveal that the heated PHB underwent an endothermic crystallization peak at around $55^{\circ} \mathrm{C}$, at which temperature there was an accommodation of chain segments that had not crystallized previously. The addition of PP to PHB, even in quantities as small as $10 \%$ in mass, inhibited the ability of PHB to crystallize exothermically during heating, and this crystallization peak was not observed in the PHB/PP blends. It is assumed that possibly, the presence of PP has the effect of diluting PHB, thereby diminishing the strength of molecular attraction between chains and allowing for their greater mobility. Thus, during cooling in the first heating cycle, all the PHB can crystallize, reducing the contribution for the permanence of crystallizable chain segments without adequate mobility in the melt ${ }^{12,13}$.

According to the DSC profiles shown in Figure 1 and Table 3, all the blends containing different amounts of PHB and PP showed a broadening of the endothermic melting peak between the $\mathrm{T}_{\mathrm{m}}$ regions of PP and PHB. This broadening is explained by the proximity of

Table 2. Injection conditions of the PHB/PP blends.

\begin{tabular}{|c|c|c|c|c|c|c|c|c|}
\hline \multicolumn{6}{|c|}{ Temperature $\left({ }^{\circ} \mathrm{C}\right)$} & \multirow{2}{*}{$\begin{array}{l}\text { Mold clamping } \\
\text { force }(\mathrm{N})\end{array}$} & \multirow{2}{*}{$\begin{array}{l}\text { Injection rate } \\
\left(\mathrm{cm}^{3} / \text { seconds }\right)\end{array}$} & \multirow{2}{*}{$\begin{array}{l}\text { Cooling time } \\
\text { (seconds) }\end{array}$} \\
\hline Zone 1 & Zone 2 & Zone 3 & Zone 4 & Zone 5 & Mold & & & \\
\hline 175 & 185 & 195 & 195 & 200 & 60 & 240 & 6 & 30 \\
\hline
\end{tabular}


the respective homopolymers' melting points, which made it impossible to attain sufficient peak resolution to confirm the presence of a melting peak at an intermediate temperature, and suggests the blends' miscibility or the existence of two distinct melting peaks that characterize the blends' immiscibility. It was also expected that, due to the difference between the melting points of PHB and PP, it would be possible, based on this thermal transition, to determine the miscibility of their blends. However, these blends presented a single melting peak, which was impossible to separate even by deconvolution techniques, at the scan velocities employed here.

\subsection{Scanning Electron Microscopy (SEM)}

Figure 2 shows the photomicrographs of PHB, PHB/PP (90/10), PHB/PP (75/25) and PHB/PP (50/50), which indicate that the PHB/ $\mathrm{PP}$ blends were immiscible in all the compositions studied here. This finding is corroborated by the PHB photomicrograph, which presents only one phase, as compared with the PHB/PP photomicrographs, which present a PP phase dispersed in the PHB matrix. The PP phase appears in the micrographs as empty spaces scattered throughout the PHB matrix, and is due to the early extraction of PP with toluene.

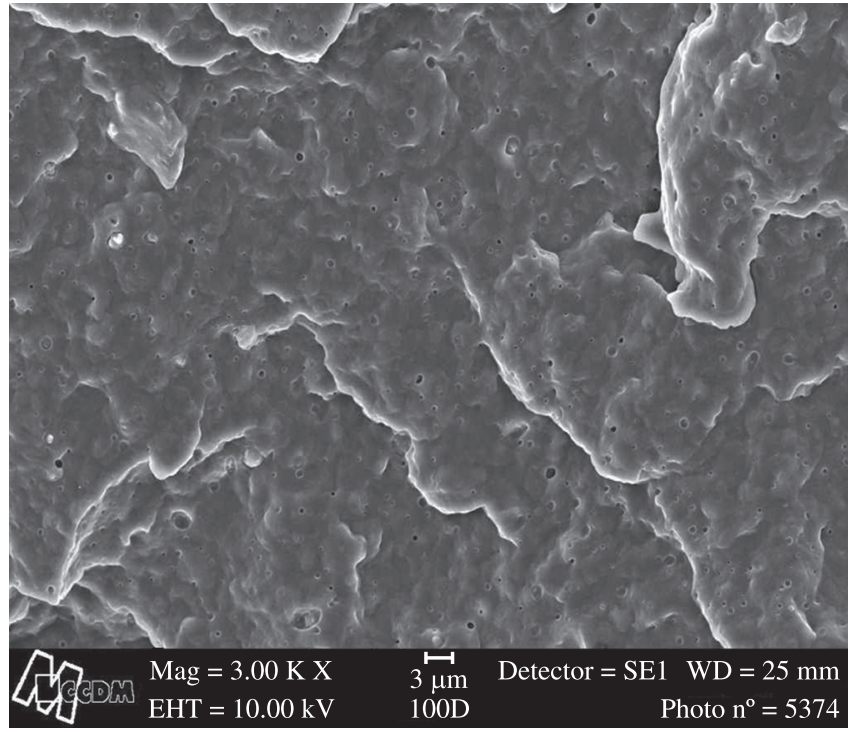

(a)

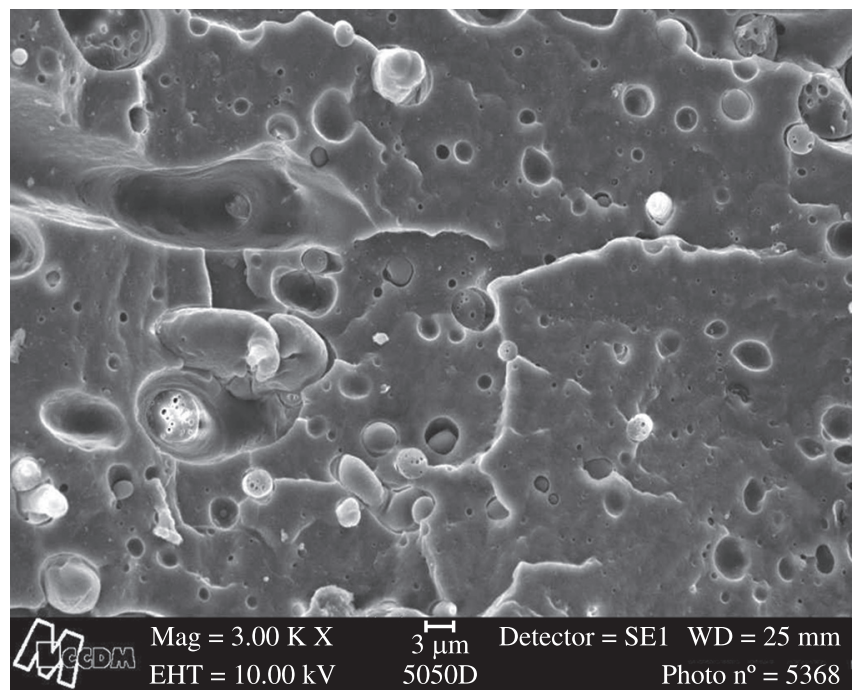

(c)

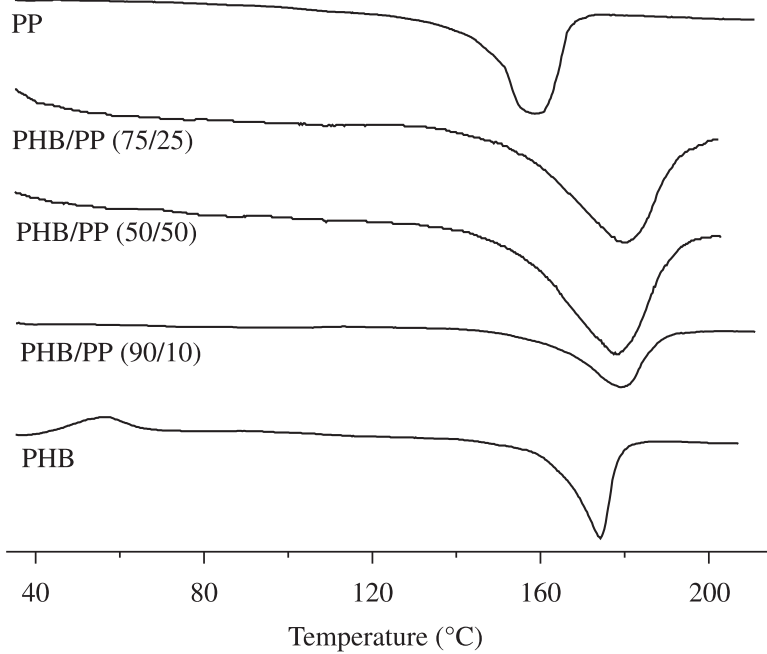

Figure 1. DSC profiles of PHB, PP and PHB/PP blends.

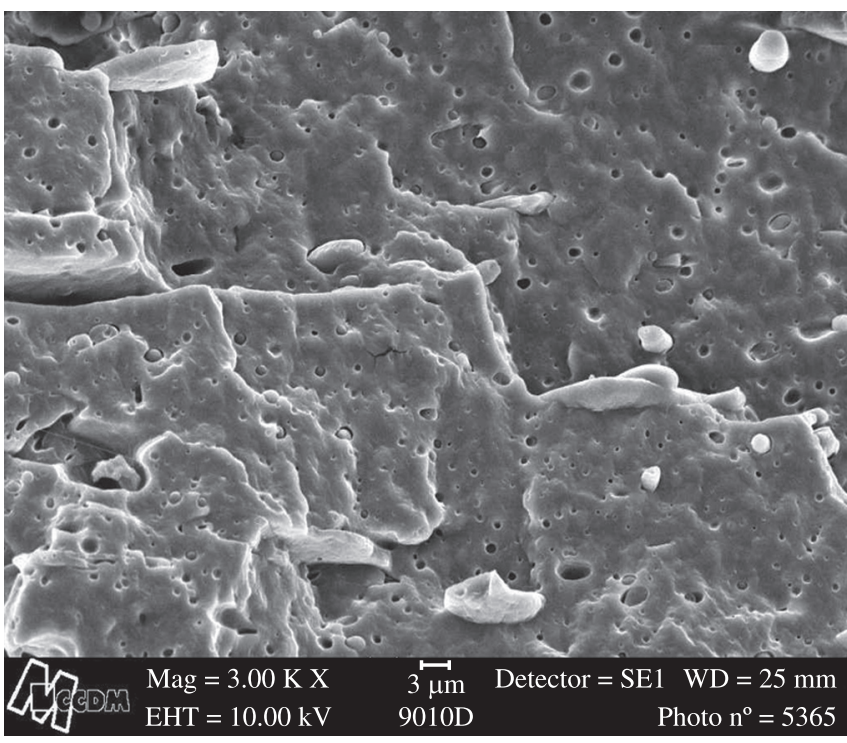

(b)

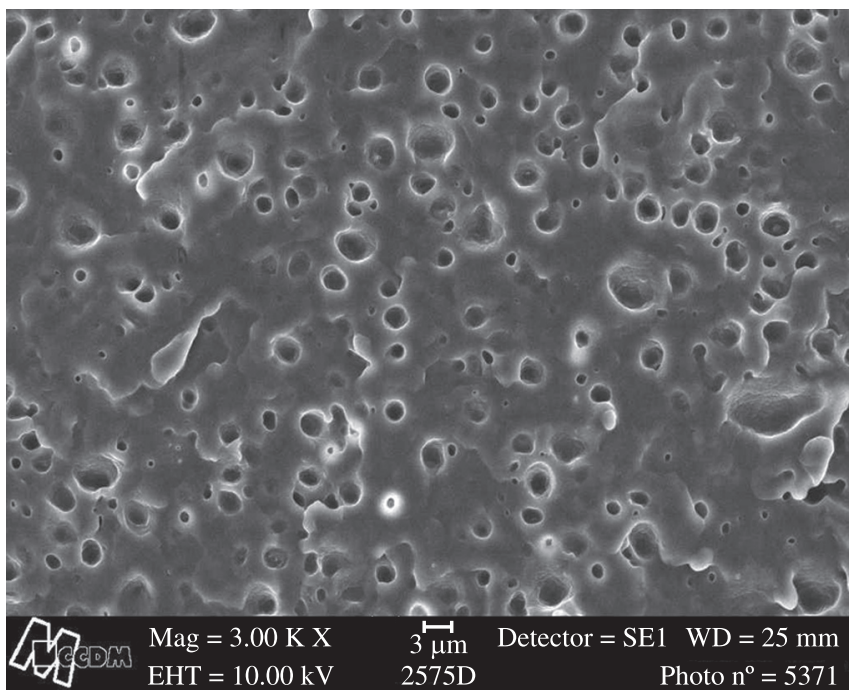

(d)

Figure 2. SEM photomicrographs of the fractured surfaces of: a) PHB; b) PHB/PP (90/10); c) PHB/PP (75/25); and d) PHB/PP (50/50). 3,000x magnification. 


\subsection{Shore D hardness}

Hardness is a measure of resistance to penetrations or scratches. The crosslinks in polymer materials increase their hardness, while plasticizers reduce it. The results in Table 4 and Figure 3 show that the mean values of hardness of the PHB/PP blends were lower than that of the pure PHB. This variation is proportional to the quantity of $\mathrm{PP}$ in the blend, and presented a shift of $13 \%$ in the PHB/PP (50/50) sample.

\subsection{Notched Izod impact tests}

The Notched Izod impact strength indicates the toughness or resistance of a rigid material to a very fast deformation. Table 5 and Figure 4 present the impact strength of PHB and its blends.

As the results in Table 5 indicate, the mean toughness values of PHB and the PHB/PP (90/10) blend are similar, suggesting that the amount of PP in this blend composition had only a negligible effect in this property.

The PHB/PP (75/25) and PHB/PP (50/50) blends showed higher mean values than that of PHB. On the other hand, note the greater increase in the toughness of the PHB/PP (75/25) composition (31\%) compared to that of PHB/PP (50/50) (18\%), which suggests that the limit of the plasticizer effect of PP lies between these two compositions.

\subsection{Tensile tests}

Table 6 lists the mean values of tensile strength. Note that, in the PHB/PP (75/25) and PHB/PP (50/50) blends, the higher proportion of

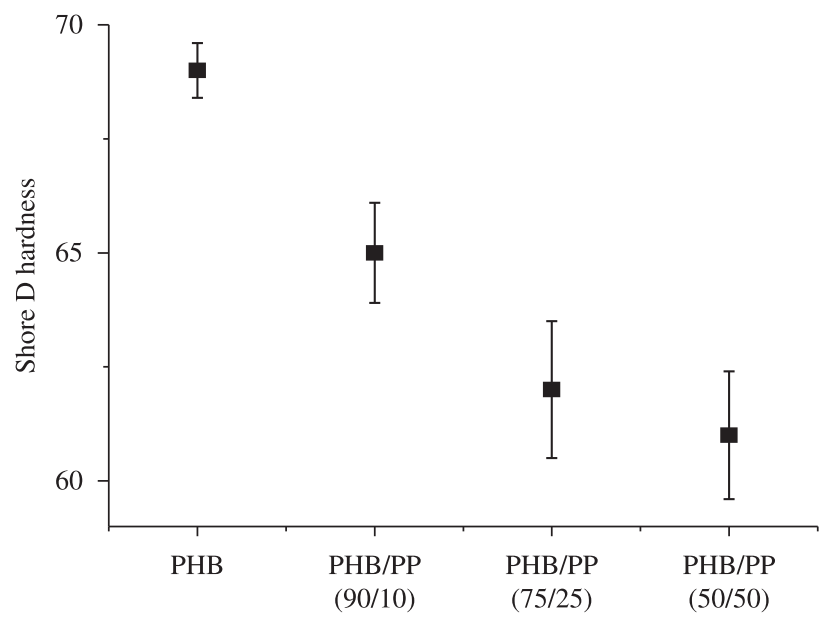

Figure 3. Shore D hardness values of $\mathrm{PHB}$ and $\mathrm{PHB} / \mathrm{PP}$ blends.

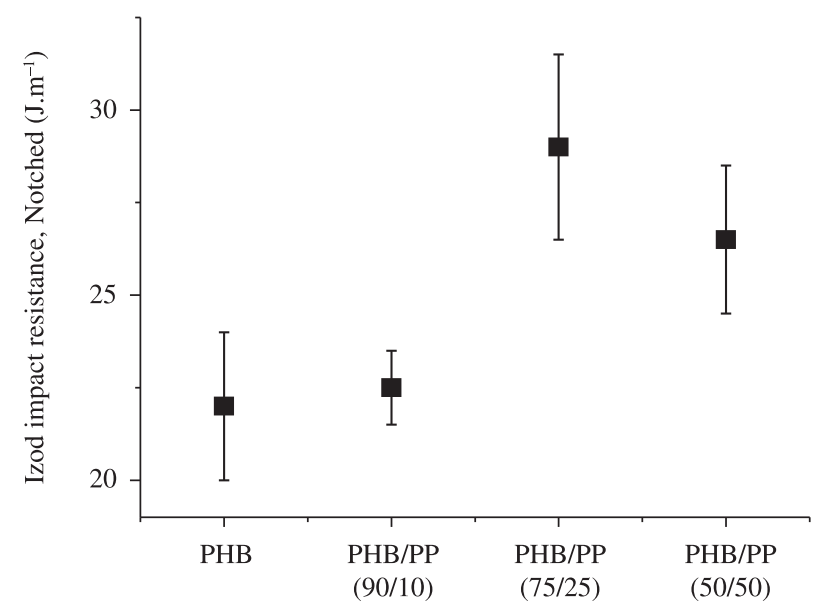

Figure 4. Notched Izod impact strength values of PHB and PHB/PP blends.
PP reduced the stiffness and fragility of PHB, causing the tensile strain at break to increase and Young's modulus and tensile strength to decrease. These results suggest a plasticizer effect resulting from the presence PP in the PHB, which was confirmed by the decrease in tensile strength.

The PHB/PP (90/10) blends showed controversial results compared with the other two formulations, in which where the influence of PP on PHB showed an antagonist character.

\subsection{Accelerated degradation in soil}

\subsubsection{Mass loss}

Figure 5 shows the mass loss of PHB during the accelerated degradation in soil, while Figure 6 shows the same results for the PHB/PP (90/10) blend. These figures indicate that both materials showed a low mass loss after ninety days. Also, note that the greatest loss mass of PHB occurred at $\mathrm{pH} 11$ (5.3\%), while that of the $\mathrm{PHB} / \mathrm{PP}$ blend occurred at $\mathrm{pH} 9(3.2 \%)$.

\subsubsection{Tensile tests}

Tables 7 and 8 show the tensile values of PHB and PHB/PP (90/10) obtained during the accelerated degradation test. These results indicate that, after ninety days of exposure in soil, the stiffness of both PHB and PHB/PP test specimens was reduced, as indicated by

Table 3. Melting temperatures of the analyzed materials.

\begin{tabular}{lc}
\hline \multicolumn{1}{c}{ Material } & $\mathrm{T}_{\mathrm{m}}\left({ }^{\circ} \mathrm{C}\right)$ \\
\hline PHB & 172 \\
PP & 162 \\
PHB/PP (90/10) & 177 \\
PHB/PP (75/25) & 180 \\
PHB/PP $(50 / 50)$ & 177 \\
\hline
\end{tabular}

Table 4. Shore D hardness values for PHB and PHB/PP blends.

\begin{tabular}{lc}
\hline \multicolumn{1}{c}{ Material } & Hardness \\
\hline PHB & $69 \pm 1$ \\
PHB/PP (90/10) & $65 \pm 1$ \\
PHB/PP (75/25) & $62 \pm 2$ \\
PHB/PP (50/50) & $61 \pm 1$ \\
\hline
\end{tabular}

Table 5. Notched Izod impact strength values for PHB and PHB/PP blends.

\begin{tabular}{lc}
\hline \multicolumn{1}{c}{ Material } & $\begin{array}{c}\text { Notched Izod impact } \\
\text { strength / J m }\end{array}$ \\
\hline PHB & $22.0 \pm 2.0$ \\
PHB/PP (90/10) & $22.5 \pm 1.0$ \\
PHB/PP (75/25) & $29.0 \pm 2.5$ \\
PHB/PP (50/50) & $26.5 \pm 2.0$ \\
\hline
\end{tabular}

Table 6. Mean tensile values of the PHB and PHB/PP blends.

\begin{tabular}{lccc}
\hline \multicolumn{1}{c}{ Material } & $\begin{array}{c}\text { Young modulus } \\
(\mathrm{MPa})\end{array}$ & $\begin{array}{c}\text { Tensile strain } \\
\text { at Break }(\%)\end{array}$ & $\begin{array}{c}\text { Tensile } \\
\text { strength }(\mathrm{MPa})\end{array}$ \\
\hline $\mathrm{PHB}$ & $2,045 \pm 85$ & $2.5 \pm 0.5$ & $28.5 \pm 0.5$ \\
$\mathrm{PHB} / \mathrm{PP}(90 / 10)$ & $1,885 \pm 40$ & $1.5 \pm 0.1$ & $24.5 \pm 0.5$ \\
$\mathrm{PHB} / \mathrm{PP}(75 / 25)$ & $1,645 \pm 20$ & $3.5 \pm 0.1$ & $27.0 \pm 0.5$ \\
PHB/PP (50/50) & $1,500 \pm 30$ & $4.5 \pm 0.1$ & $27.5 \pm 0.5$ \\
\hline
\end{tabular}




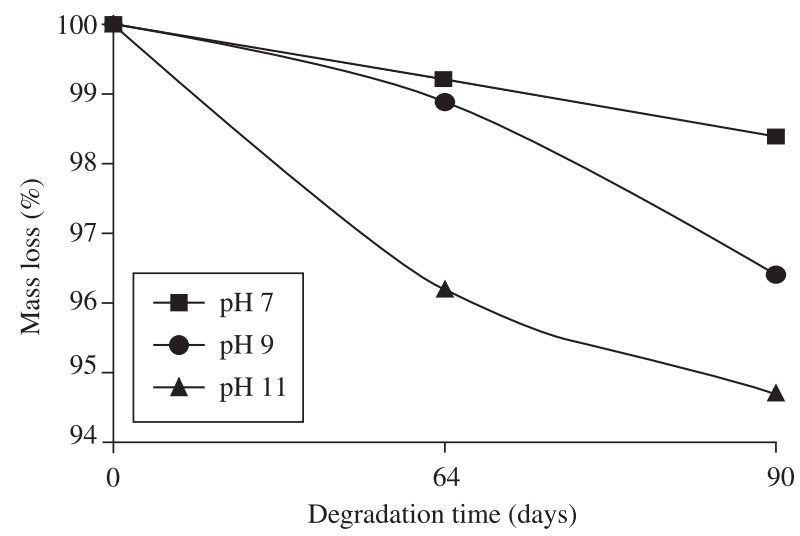

Figure 5. PHB mass loss due to accelerated degradation.

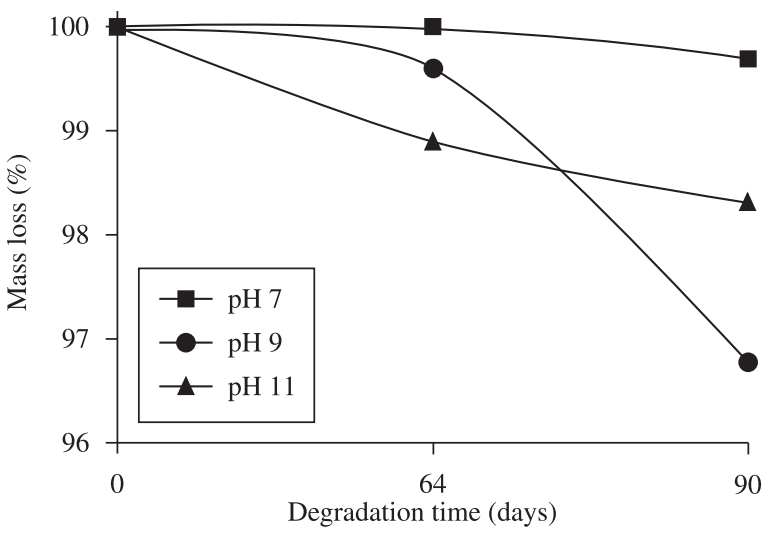

Figure 6. PHB/PP (90/10) mass loss due to accelerated degradation.

Table 7. Mechanical properties of PHB after accelerated degradation in soil.

\begin{tabular}{lccc}
\hline & $\begin{array}{c}\text { Young modulus } \\
(\mathrm{Mpa})\end{array}$ & $\begin{array}{c}\text { Tensile strain } \\
\text { at break (\%) }\end{array}$ & $\begin{array}{c}\text { Tensile strength } \\
(\mathrm{Mpa})\end{array}$ \\
\hline Not degraded & 2,043 & 2.64 & 28.40 \\
pH 7 & 1,590 & 2.69 & 23.19 \\
pH 9 & 1,567 & 2.71 & 22.96 \\
pH 11 & 1,551 & 2.49 & 22.19 \\
\hline
\end{tabular}

Table 8. Mechanical properties of PHB/PP (90/10) after accelerated degradation in soil.

\begin{tabular}{lcc}
\hline & $\begin{array}{c}\text { Maximum load } \\
(\mathrm{kgf})\end{array}$ & $\begin{array}{c}\text { Young modulus } \\
(\mathrm{MPa})\end{array}$ \\
\hline Not degraded & 103.0 & 1,888 \\
pH 7 & 97.0 & 1,590 \\
pH 9 & 96.0 & 1,567 \\
pH 11 & 93.4 & 1,551 \\
\hline & Tensile strain at break & Tensile strength \\
& $(\%)$ & $(\mathrm{MPa})$ \\
\hline Not degraded & 1.62 & 24.5 \\
pH 7 & 2.69 & 23.2 \\
pH 9 & 2.71 & 22.7 \\
pH 11 & 2.50 & 22.2 \\
\hline
\end{tabular}

the decrease in Young's modulus and tensile strength and the increase in tensile strain at break.

\subsubsection{Visual appearance}

Figures 7 and 8, respectively, depict the appearance of PHB and PHB/PP (90/10) test specimens after ninety days of accelerated degradation in soil. The photographs clearly show that the degradation process was superficial. This superficial attack caused micro-erosions on the surfaces of the test specimens, increasing their porosity and reducing their mechanical stiffness.

These Figures also show that both PHB and PHB/PP became markedly degraded in the alkaline medium. This is explained by the increase in the hydrolytic degradation rate of $\mathrm{PHB}$, which is catalyzed in alkaline media.

\section{Conclusions}

All the PHB and PP blends presented immiscibility. This immiscibility was confirmed by the SEM photomicrographs but could not be ascertained by DSC due to the proximity of the PHB and PP melting points, which prevented a satisfactory resolution.

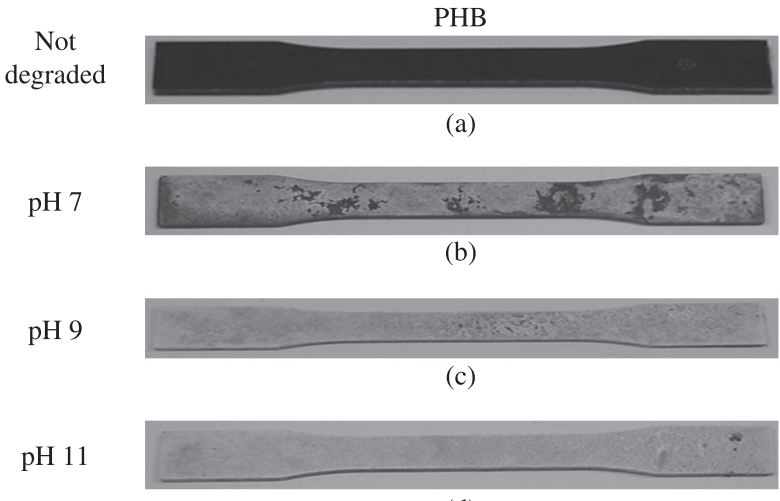

(d)

Figure 7. Photographs of the PHB specimens: a) before degradation tests, and after degradation tests in soil with varying $\mathrm{pH}$; b) $\mathrm{pH} 7$; c) $\mathrm{pH}$ 9; and d) $\mathrm{pH} 11$.

\section{PHB/PP (90/10)}

Not
degraded

$\mathrm{pH} 7$

pH 9

pH 11

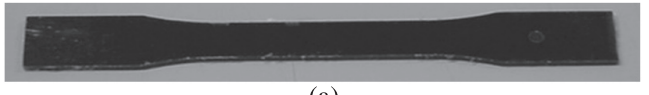

(a)

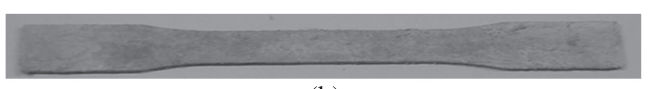

(b)

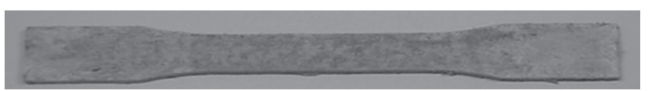

(c)

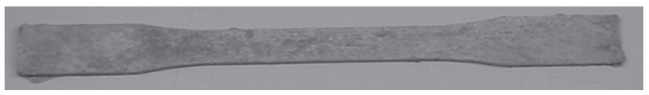

(d)

Figure 8. Photographs of the PHB/PP (90/10) specimens: a) before degradation tests, and after degradation tests in soil with varying $\mathrm{pH}$; b) $\mathrm{pH} 7$; c) $\mathrm{pH} 9$; and d) $\mathrm{pH} 11$. 
The PHB/PP blends showed a tendency for decreasing crystallinity and stiffness of the PHB matrix and increasing flexibility as a function of the amount of PP in the formulation.

Both PHB and PHB/PP (90/10) presented traces of degradation during the accelerated degradation tests, which was indicated by their mass loss and their diminished mechanical properties. This degradation was also found to be more marked in alkaline $\mathrm{pH}$, since an alkaline medium favors the hydrolytic degradation mechanism of PHB. More than ninety days are required for PHB to become totally degraded, and hence for a better evaluation of the degradation behavior of the PHB/PP (90/10) blend.

\section{Acknowledgements}

The authors would like to thank CAPES and CNPq (Brazil) for their financial support. We are also indebted to PHB Industrial S/A for supplying the PHB, and Quattor Petroquímica S/A for providing the PP used in this work.

\section{References}

1. Albertssson AC, Huang SJ. Degradable polymers, recycling and plastics waste management. 1 ed. New York: CRC; 1995.

2. Scott G, Gillead D. Degradable polymers. 1 ed. London: Chapman \& Hall; 1995.

3. Sharma R, Ray AR. Polyhydroxybutyrate, its copolymers and blends. Journal of Macromolecular Science - Reviews in Macromolecular Chemistry \& Physics 1995; C35(2): 327-359.

4. Griffin JL. Chemistry and technology of biodegradable polymers. 1 ed. London: Springer; 1993.
5. Asrar J, Gruys K. Biodegradable polymer (Biopol) in: biopolymers, Vol. 4 - Polyesters III: applications and commercial products. 1 ed. Weinheim: Wiley-VCH; 2004.

6. Kopinke FD, Remmler M, Mackenzie K. Thermal decomposition of biodegradable polyesters --I: Poly( $\pm \mathrm{b}$-hydroxybutyric acid). Polymer Degradation and stability. 1996; 52(1):25-38.

7. Abbate M, Martuscelli E, Ragosta G, Scarinzi G. Tensile properties and impact behavior of poly(D(-)3-hydroxybutyrate)/rubber blends. Journal of Material Science. 1991; 26(4):1119-1125.

8. Greco P, Martuschelli E. Crystallization and thermal behavior of poly(D(-)3-hydroxybutyrate)-based blends. Polymer. 1989; 30(8):1475-1483.

9. Avella M, Martuscelli E, Greco P. Crystallization behavior of poly(ethylene oxide) from poly(3-hydroxybutyrate)/poly(ethylene oxide) blends: phase structuring, morphology and thermal behaviour. Polymer. 1991; 32(9):1647-1653.

10. Avella M, Martuscelli E. Poly-d-(-)(3-hydroxybutyrate)/poly(ethylene oxide) blends: phase diagram, thermal and crystallization behavior. Polymer. 1988; 29(10):1731-1737.

11. Avella M, Martuscelli E. Poly(3-hydroxybutyrate)/poly(methyleneoxide) blends: thermal, crystallization and mechanical behavior. Polymer. 1997; 38(25):6135-6143.

12. Xing P, Ai X, Dong L, Feng Z. Miscibility and crystallization of poly(3- hydroxybutyrate)/poly(vinyl acetate-co-vinyl alcohol) blends. Macromolecules. 1998; 31(20):6898-6907.

13. Xing P, Dong L, An Y, Feng Z, Avella M, Martuscelli E. Miscibility and crystallization of poly(3-hydroxybutyrate) and poly(p-vinylphenol) Blends. Macromolecules. 1997; 30(9):2726-2733. 